\title{
Information Society: the two faces of Janus
}

\author{
Michalis Vafopoulos \\ Department of Cultural Technology and Communication, \\ University of the Aegean, Faonos St., 81100 Mytilini, Greece. \\ vaf@acgean.gr
}

\begin{abstract}
Knowledge could be considered as the most critical dual factorinput and output - in production and scientific processes. Strategic and influential use of Information and Communication Technologies (ICTs) - the so called Information Society (IS) - reveals vast potential in knowledge production and economic development. In our point of view, two are the key issues in effective ICTs exploitation: (a) social consensus about quantity, quality and processing mechanisms of public information and (b) transformation process path between the general e-work model and the g-work paradigm. In this context, the knowledge-based development codifies the positive face of IS, in contrast to personal data abuse. The concept of the "new democratic deficit" is introduced in order to move into the foreground the significant dialectic relationship between ICTs and society.
\end{abstract}

\section{Introduction}

IS is a political and scientific concept, since ICTs affect in a horizontal way many aspects of our life. In the first section, the Data Information Knowledge and Wisdom Hierarchy (DIKW) is described. The origins and evolution of the IS concept are presented in the next section. Third section is devoted in the double face of Janus which characterizes the IS in practice. The positive aspect refers to the knowledgebased development as it is described by the g-work analytical framework. Personal data abuse by legal or illegal authorities constitutes the negative face of the IS.

\section{Data - Information - Knowledge}

The Data Information Knowledge and Wisdom Hierarchy (DIKW) - or the "Knowledge or Information Hierarchy" or the "Knowledge Pyramid" - was initiated by Milan Zeleny [1] and builds on the equation of Data, Information, Knowledge and Wisdom to "know-nothing", "know-what", "know-how" and "know-why", respectively. The mainstream view with few variations is that data is raw numbers

Please use the following format when citing this chapter:

Vafopoulos, Michalis, 2006, in IFIP International Federation for Information Processing, Volume 204, Artificial Intelligence Applications and Innovations, eds. Maglogiannis, I., Karpouzis, K., Bramer, M., (Boston: Springer), pp. 643-648 
and facts, information is processed data, and knowledge is authenticated information $[2,3,4]$. Specifically, data is raw in any form, - functional or not - and has no meaning beyond its existence. Information is meaningfully interrelated data. A certain meaning can be - not necessarily - valuable. In computer and information sciences, relational databases and data interoperability technologies (mainly XML, RDF, OWL $[12,14]$ and SKOS $[13,14]$ ) enable the data - information conversion. Knowledge is structured information for facts, procedures, concepts, interpretations, observations, and theories. Wisdom is considered to be a human process by which we evaluate right and wrong, good and bad knowledge.

Last decades, the evolution and wide dissemination of digital goods $[5,6,33]$ triggered an information overload $[7,8,9,10]$ since data, information and knowledge could be primarily analyzed as the most famous digital goods. Social consequences of the technological advances are commonly codified by the Information Society (IS) concept.

\section{Information Society}

According to Susan Crawford [30] scientists have systematically been considered the increase of publications in the seventeenth and nineteenth century $[15,16]$, but the concept of "Information Society" was initiated by the economist Fritz Machlup in 1962. Machlup in his milestone book called "The Production and Distribution of Knowledge in the United States" [17] analyzed the imperfections of competition in a free society. The basic aspects of his study were the causal interrelation among the cost of copyrights and Research and Development (R\&D) and knowledge production. His conceptualization for the knowledge process was consisted of (a) $\mathrm{R} \& \mathrm{D}$, (b) Education, (c) Communication and its media and (d) Information machines and services. Based on this approach he studied the share of information as a component of the Gross National Product (GNP) of the United States and he found - among many interesting results - that the aggregate knowledge production made up $29 \%$ of the adjusted GNP and the total civilian labor force engaged in knowledgeproducing activities in the United States was equal to $42.8 \%$ in 1969.

Machlup's ideas inspired a series of other authors, but profoundly Peter Drucker [18], which introduced the concept of "Knowledge Society" and predicted that by the late $1970 \mathrm{~s}$, the knowledge sector would account for one half of the GNP. The concept of Information Society (IS) was established in the annual meeting of American Society for Information Science in 1970, which was entitled as "The Information-Conscious Society" meeting [19].

Last decades, fast advances in the Information and Communication Technologies (ICTs) triggered wide research efforts about IS in economic studies and computer and social sciences. The disciplines of Knowledge Management [11] and Social Informatics [20] have emerged and Artificial Intelligence [42] and Knowledge Engineering [43] revitalized. The concept of IS enriched by traditional social theories, such as Marxist-inspired or post-Marxist theories, more or less critical theories of modernity and/or postmodernity, or theory of structuration $[21,22]$. Analysis of the informational network society initiated by Manuel Castells 
$[23,24,25,26,27]$ is shaping a new framework based on analytical resources developed in modern social theory and new political economy. Related terms to IS are considered to be Digital Society [31] and Virtual Society [28].

We are still far away from a general theory for the IS. In my point of view, IS needed to be addressed in a trans-disciplinary framework, a step further to interdisciplinarity, based on an integrated view of different disciplinary epistemologies. According to Vafopoulos et al [29] "In trans-disciplinary research, the point is not just application of given methodologies but also implication, a result of imagining entirely new possibilities for what disciplines can do. The 'trans' in transdisciplinarity is about recognizing the holistic approach of this process of investigation which trans-forms mainstream definitions of research".

In this context, the first step in the trans-disciplinary framework is considered to be the analysis of the positive and the negative consequences in the modern IS.

\section{The two faces of Janus: Knowledge vs. Control}

In the current analysis, the positive face of Janus is reflected in the knowledge-based development and the negative is referred to personal privacy violation issues.

\subsection{Knowledge - based development and the g-work model}

Knowledge is synchronously the most valuable input and output in the process of economic development. Despite the fact that nowadays knowledge is characterized by excess supply and is under - used, mainly because it can not be accumulated like an ordinary good [32]. Danny Quah [32] points out that "As humanity becomes more educated, and ideas, tastes, and beliefs integrate more closely, the greater become the potential social benefits from deploying all the different kinds of knowledge - those that increase our productivity, improve our health, and raise our quality of life".

In this context, ICTs can be viewed as an opportunity to obtain economies of scale in the knowledge production and dissemination process. Particularly, digital goods - including knowledge - are nonrival, infinitely expansible, indivisible, aspatial and recombinant [33], Semantic Web technologies [34] provide knowledge interoperability and reprocess, high tech collaborative working environment applications offer quasi face-to face almost costless meetings and Grid computing is releasing vast amounts of processing power [35].

A comprehensive analytical and practical framework for knowledge creation, reuse and exploitation in the personal, business and academic sector based on the Semantic Grid technologies [36] is considered to be g-work [14]. G-work is defined to be a step further to e-work [37]. G-work was introduced as a personal Grid eworkspace for every citizen and was defined to have four interconnected parts: (a) Digital Storage, (b) Network Traffic, (c) Processing Power and (d) One-stop Web Services. As Vafopoulos et al [14] argues, today business practice is compatible to gwork, web services for all citizens are being released everyday around the world and academia - specifically life, computer and information sciences - is adapting to this innovative operational model [38]. 
But in any case, it is not ICTs themselves but the way people use them that influences whether or not and how ICTs gets actually used. Furthermore, in case of social and economic reforms, it is not just the technology itself but the motivation for people to co-operate each other.

\subsection{Control society, surveillance and personal data privacy}

The development concept is concentrated in an opportunity: more and better input in every citizen's information set, and a threat: personal data privacy. The trade-off is not conspicuous but is fundamental: more personal data in a collaborative working environment means more chances to work, co-operate, interact, learn and develop your personality, but also increase possibilities for personal data abuse. In the above trade - off

the September 112001 terrorist attacks on New York and Washington are considered as a turning point since security and surveillance operations - including e-mail and Internet monitoring - [39] become first priority in public policies and funding. Before that key date, studies on the social impact of surveillance and monitoring systems were concentrated in the concept of centralized power [40]. According to David Lyon [39] "The increasingly automated discriminatory mechanisms for risk profiling and social categorizing represent a key means of reproducing and reinforcing social, economic, and cultural divisions in informational societies".

Hacking [41] and inventions in software systems poses the other major category of risks for personal data privacy. Widespread use of ICTs in everyday life drives a substantial increase in the value of legality which in turn follows a correspondent increase in the law-breaking activity. The major issue in this case is that benefits coming from the IS are divided into a vast and loosely - connected group of people with not necessarily common interest and action plan. On the contrary, benefits from law-breaking activity in the IS framework are exploited by small, flexible and well organized teams. The above asymmetrical value function for the adaptation of information technologies partially explains observed time and technology lags in public compared to private Web Services technologies.

In the g-work framework [14], besides the technical aspect of data privacy (i.e. semantic firewalls and Community Authorization Service for Group Collaboration), an independent "third intermediator entity" run by representatives from local authorities is proposed.

\section{Policy implications}

Information Society is a political and scientific concept, since ICTs shaped by society and shape society. Society - ICTs dialectic relation until now has been given less attention. IS is becoming the major aspect in personal, social, business and scientific life. 


\subsection{Personal and social aspect}

The key concept in the personal and social aspects of the IS is introduced to be "the new democratic deficit". The new democratic deficit is defined to have two dimensions:

1. the lack of free access to structured information and knowledge concerning public action for all citizens and

2. unauthorized and nonvoluntary access to personal data from third parties.

For instance, democratic deficits exist when a government service is not available for a group of citizens or a telephone call is recorded without legal authorization.

\subsection{Research and business aspect}

The research and business aspect of the IS is focused in the transition from the general e-work model to the g-work paradigm. Specifically, from e-work which is "including all information-processing work carried out away from the establishment using a computer and a telecommunications link to deliver the work" [37], nowadays, scientists and businessmen are trying to g-work, namely to semantically interoperate with people, knowledge, software and hardware.

In order to exploit the benefits of IS we should agree on specific standards on the:

- quality,

- quantity and

- knowledge formation tools and mechanisms of public information.

Quality refers to interoperability and reusability standards of information in order to solve everyday problems with minimum cost. Quantity mainly involves the discrimination between personal and public information. Knowledge formation tools include software and organizational structures capable to transform raw data and information to useful knowledge.

\section{Conclusion}

ICTs by augmenting human senses change and/or remove limits among social structures. Since this basic finding seems not to be fully appreciated by the majority of politicians, academia owes to guide the way through an efficient and fair IS exploitation. Social and technology scientists should work together without technological or social monolithic determinism in order to achieve sustainable development for human societies.

\section{References}

1. Zeleny, M.: Management Support Systems: Towards Integrated Knowledge Management, Human Systems Management, 71 (1987), 59-70

2. Dretske, F.: Knowledge and the Flow of Information, MIT Press, Cambridge, MA. (1981) 
3. Machlup, F.: Knowledge: Its Creation, Distribution, and Economic Significance, Volume I, Princeton University Press, Princeton, NJ. (1980)

4. Vance, D.: Information, Knowledge and Wisdom: The Epistemic Hierarchy and ComputerBased Information System, in Proceedings of the Third Americas Conference on Information Systems, B. Perkins and I. Vessey (eds.), Indianapolis, IN, (1997)

5. Quah, D.: A weightless economy. UNESCO Courier (1998)

6. Quah, D.: Increasingly weightless economies. Bank of England Quarterly Bulletin, 37(1) (1997) 49-56

7. Berghel, H.: Cyberspace 2000: dealing with information overload, Communications of the ACM 40 (2) (1997) 19-24

8. Kirsh, D.: A few thoughts on cognitive overload. Intellectica (2000)

9. Lewis, D.: Dying for Information? London: Reuters Business Information (1996)

10. Feather, I.: In The information society: A study of continuity and change. London: Library Association (1998)

11. Alavi, M., Leidner, D.: Knowledge Management Systems: Emerging Views and Practices from the Field. Communications of the AIS (1999)

12. Gil, Y., Ratnakar V.: A Comparison of (Semantic) Markup Languages. Proceedings of the International FLAIRS Conference, Pensacola Beach, Florida, May 14-16 (2002) http://trellis.semanticweb.org/expect/web/semanticweb/comparison.html.

13. Simple Knowledge Organisation System (SKOS), W3C Semantic Web Activity (2005) http://www.w3.org/2004/02/skos/

14. Vafopoulos, M., Gravvanis, G., Platis, A.: The personal grid e-workspace, In: Grid Technologies: Emerging from Distributed Architectures to Virtual Organizations, M.P. Bekakos, G.A. Gravvanis and H.R. Arabnia, (eds) WIT Press, (2005)

15. Kronick, D.: A history of scientific and technical periodicals. Metuchen, NJ: Scarecrow Press (1962)

16. Billings, J. S.: Selected papers. Chicago: Medical Library Association (1965)

17. Machlup, F.: The production and distribution of knowledge in the United States. Princeton, NJ: Princeton University Press (1962)

18. Drucker, P.: The age of discontinuity. New York: Harper \& Row (1968)

19. Proceedings of the American Society for Information Science. Washington, D.C.: ASIS, (1970)

20. Kling, R., Crawford, H., Rosenbaum, H, Sawyer, S., Weisband, S.: Learning from Social Informatics: Information and Communication Technologies in Human Contexts Centre for Social Informatics, Indiana University (2000)

21. Giddens, A.: The Constitution of Society. Outline of the Theory of Structuration. Polity Press, (1986)

22. Giddens, A.: The Consequences of Modernity. Polity Press, (1992)

23. Castells, M.: High Technology, Economic Restructuring, and the Urban-Regional Process in the United States. In Manuel Castells (ed.) High Technology, Space, and Society. Urban Affairs Annual Reviews, Volume 28. SAGE Publications. (1985)

24. Castells, M.: The Informational City. Information Technology, Economic Restructuring, and the Urban-Regional Process. Oxford: Basil Blackwell (1989)

25. Castells, M.: The Information Age. Economy, Society and Culture. Vol. I: The Rise of the Network Society. Oxford: Blackwell (1996)

26. Castells, M.: The Information Age. Economy, Society and Culture. Vol. II: The Power of Identity. Oxford: Blackwell (1997) 